García, W., y Bedoya, O. (2020). El debido proceso en la liquidación de revisión: garantías procesales para el responsable, agente retenedor o declarante. Contaduría Universidad de Antioquia, 77, 221-248.

Doi: https://doi.org/10.17533/udea.rc.n77a08

\title{
El debido proceso en la liquidación de revisión: garantías procesales para el responsable, agente retenedor o declarante
}

William Andrés García Ospina

Universidad de Antioquia

wandres.garcia@udea.edu.co Orcid: 0000-0001-7744-9795

Omar Hernando Bedoya Martínez

Universidad de Antioquia omar.bedoya@udea.edu.co Orcid: 0000-0003-0683-2986 
EI debido proceso en la liquidación de revisión: garantías procesales para el responsable, agente retenedor o declarante

Resumen: El debido proceso como garantía constitucional judicial y administrativa rige en materia tributaria cuando la administración supone que la liquidación privada se realizó con el desconocimiento de los hechos configuradores de un impuesto o indebida aplicación normativa. Esta fiscalización tributaria debe garantizar el debido proceso y el derecho de defensa como garantía a los derechos de los ciudadanos. El propósito de este estudio se centra en complementar los conocimientos contables en materia impositiva con un análisis jurisprudencial del debido proceso que nos permite concluir que se requiere mayor apropiación del conocimiento por parte de los ciudadanos a fin de realizar una correcta defensa de sus intereses en la discusión del tributo. Se realizó un análisis jurisprudencial a la luz de las normas tributarias que ha construido la Corte Constitucional, pero, igualmente, el Consejo de Estado y la Dirección de Impuestos y Aduanas Nacionales.

Palabras clave: Debido proceso, presunción de inocencia, liquidación de revisión, fiscalización tributaria, defensa técnica.

Due process in tax settlement review: procedural guarantees for the responsible of tax, tax withholding or tax declaring agent

Abstract: Due process as a constitutional, judicial and administrative guarantee rules in tax matters when the administration assumes that the private settlement was made without knowledge of the facts configuring a tax or with undue application of the regulation. This tax audit must guarantee due process and the right to defense as a guarantee of citizens' rights. The purpose of this study is focused on complementing accounting knowledge in tax matters with a jurisprudential analysis of due process which allows to conclude that greater appropriation of knowledge by citizens is required in order to carry out a duly defense of their interests in tax discussion. A jurisprudential analysis was carried out in the light of tax norms that have been built by the Constitutional Court, the Council of State and the National Tax and Customs Administration.

Keywords: Due process, presumption of innocence, review settlement, tax inspection, technical defense.

O devido processo na liquidação de revisão: garantias processuais para o presponsável, agente de retenção ou declarante

Resumo:O devido processo como garantia constitucional judicial e administrativa rege em contexto tributário quando a administração supõe que a liquidação privada foi realizada com o desconhecimento dos fatos configurados de um imposto ou indevida aplicação normativa. Esta fiscalização tributária deve garantir o devido processo e o direito de defesa como garantia aos direitos dos cidadãos. O propósito deste estudo centra-se em complementar os conhecimentos contábeis em matéria impositiva com uma análise jurisprudencial do devido processo que nos permite concluir que se requer maior apropriação do conhecimento por parte dos cidadãos a fim de realizar uma correta defesa de seus interesses na discussão do tributo. Realizou-se uma análise jurisprudencial à luz das normas tributárias que tem construído a Corte Constitucional, mas, igualmente, o Conselho de Estado e a Direção de Impostos e Alfândegas Nacionais.

Palavras chave: Devido processo, presunção da inocência, liquidação de revisão, fiscalização tributária, defesa técnica.

La procédure régulière dans la liquidation de la révision: garanties procédurales pour le responsable, l'agent chargé de la rétention ou le déclarant

Résumé: La procédure régulière en tant que garantie constitutionnelle, judicière et administrative est applicable en matière fiscale lorsque l'administration présuppose que la liquidation privée a été effectuée dans l'ignorancedes constitutifs d'un impôt ou par l'application inappropriée de la réglamentation. Ce contrôle fiscal doit garantir une procédure régulière et les droits de la défense en tant que garantie des droits des citoyens. Le but de cette étude est de compléter les connaissances comptables en matière fiscale par une analyse jurisprudentielle de la régularité de la procédure, ce qui nous permet de conclure que l'appropriation des connaissances par les citoyens est nécessaire pour réaliser une défense correcte de leurs intérêts dans la discussion de l'impôt. Une analyse jurisprudentielle a été effectuée à la lumière des règles fiscales établies par la Cour Constitutionnelle Colombienne, mais aussi par le Conseil d'État et la Direction des impôts et des douanes nationales de Colombie.

Mots-Clés: Procédure réguliêre, présomption d'innocence, liquidation de revisión, contrôle fiscal, défense technique. 


\title{
El debido proceso en la liquidación de revisión: garantías procesales para el responsable, agente retenedor o declarante
}

\author{
William Andrés García Ospina y Omar Hernando Bedoya Martínez. \\ https://doi.org/10.17533/udea.rc.n77a08
}

Primera versión recibida en noviembre de 2019 - Versión aceptada en julio de 2020

\section{Introducción}

Colombia es un Estado Social de Derecho, regido por principios y normas de la Constitución Política de 1991, que establecen los lineamientos para el ejercicio de la actividad financiera e incluyen el poder fiscal de la Nación y de las entidades territoriales, cuyo objetivo es regular los ingresos, el gasto público, la facultad de imponer tributos y recaudarlos, y cumplir así con los objetivos que la Carta le traza. La imposición de tributos solo puede hacerse mediante una ley que determine, de manera abstracta, las actividades que se someten al régimen impositivo, las tarifas que operan y la periodicidad con que deberán pagarse. El recaudo, por su parte, se realiza voluntaria o impositivamente. El poder tributario comporta el de fiscalización sobre las declaraciones y la autoliquidación que realizan los contribuyentes.

En todas las etapas rige el debido proceso, que la Constitución Política establece como derecho fundamental de las personas, frente a las actuaciones judiciales y administrativas y que aplica al poder fiscal y tributario del Estado que deberá seguir las normas constitucionales pues son el límite a sus actuaciones.

Entre los procedimientos tributarios autorizados constitucional y legalmente está el que define cuándo, por cuál funcionario y a causa de qué hay lugar a la liquidación de revisión por parte de la Dirección de Impuestos y Aduanas Nacionales -DIAN- cuando encuentra que la liquidación del impuesto, de una persona natural o jurídica, no corresponde a la realidad económica.

La liquidación de revisión es un acto administrativo en el cual, previa la respuesta del ciudadano al Requerimiento Especial, la entidad propone 
García, W., y Bedoya, O. El debido proceso en la liquidación de revisión...

la modificación de los valores declarados por el contribuyente, por el responsable, el agente retenedor o el declarante, cuando jurídicamente existan presupuestos jurídicos o de hecho que sustentan un cuestionamiento oficial y no son respondidos con claridad. El antecedente que da lugar a la liquidación de revisión es el incumplimiento de obligaciones tributarias por conductas de evasión o de elusión y la información de las conductas en cada caso se obtiene mediante la fiscalización tributaria.

Los resultados de la fiscalización concluyen con la liquidación y el proceso que se realiza, con un acto administrativo complejo con apego a lo establecido por los artículos 702 al 714 del Estatuto Tributario, pertenecientes al Título Tres del Libro Quinto. Además de cumplir con lo establecido en los artículos mencionados, deberá cumplir con las exigencias del Código de Procedimiento Administrativo y de lo Contencioso Administrativo, y con las normas y principios que rigen el debido proceso.

Se trata de una actuación jurídica compleja, susceptible de violar las garantías del debido proceso. En este artículo se indaga sobre el trámite de la liquidación de revisión que emite la DIAN cuando encuentra que la Liquidación Privada no corresponde a la realidad. Se analiza este momento procesal y se pregunta si hay equilibrio entre la garantía para el ciudadano de que sus derechos no serán vulnerados y el ejercicio del poder tributario del Estado.

Para dar cuenta de este problema se debe establecer el conjunto de principios, deberes y derechos que tanto la Constitución Política como la Ley consagran en relación con el debido proceso en el derecho tributario, en sede administrativa, a la luz de la jurisprudencia constitucional y contenciosa administrativa.

Es necesario para todo profesional que ejerce el derecho contable y tributario conocer el soporte constitucional y legal del debido proceso, aplicable al caso de la liquidación de revisión con el fin de tener elementos de defensa.

\section{Significado del debido proceso}

Los estados contemporáneos se someten a sus propias normas como garantía de los derechos ciudadanos. Pero, no siempre ha sido así. En los estados monárquicos anteriores a los regímenes liberales imperaron normas proferidas por el monarca quien las modificaba según las necesidades organizativas del reino, o de su voluntad. Los impuestos se decretaban y cobraban sin ordenación jurídica, según López y Gutiérrez (2001), y no existía distinción entre el patrimonio del monarca y el erario; de tal modo que los súbditos estaban obligados indistintamente a remediar las necesidades estatales y las del rey.

En el Estado liberal de derecho se adoptó como principio fundamental el apego a ley, que según Montesquieu es: "la razón humana en cuanto se aplica al 
gobierno de todos los pueblos de la tierra” (1906, p. 18). Acatar la ley significó precisar los derechos y deberes del ciudadano y someter los actos estatales al escrutinio de jueces independientes, de conformidad con la separación de poderes, que constituyó una limitación al poder público.

En Colombia, en 1991, la nueva Constitución Política adoptó la forma del Estado Social de Derecho. Sus normas son la fuente principal del derecho que les asigna contenido a las demás, como lo expresa Cea E. (2007), con un sistema basado en el respeto y garantía de los derechos que defienden la ley y la jurisprudencia.

\section{El principio de legalidad en Colombia}

El Estado Social de Derecho según el artículo $1^{\circ}$ de la Constitución, obedece al principio de legalidad, que, en palabras de Chinchilla (2016):

En su más rigurosa aplicación, este principio exige que todo acto del órgano del Estado debe tener un referente jurídico previo, un sustento normativo expreso que le brinde justificación legitimadora (de todas formas, es un mecanismo ideológico que funciona socialmente). (p. 46)

Y la Corte Constitucional lo ha reafirmado en su Sentencia C-710:

El principio constitucional de la legalidad tiene una doble condición: de un lado es el principio rector del ejercicio del poder y del otro, es el principio rector del derecho sancionador. Como principio rector del ejercicio del poder se entiende que no existe facultad, función o acto que puedan desarrollar los servidores públicos que no esté prescrito, definido o establecido en forma expresa, clara y precisa en la ley. Este principio exige que todos los funcionarios del Estado actúen siempre sujetándose al ordenamiento jurídico que establece la Constitución y lo desarrollan las demás reglas jurídicas. (Corte Constitucional [Magistrado ponente: Jaime Córdoba Triviño], 2001)

Significa que el propio Estado se ha sometido a las normas expedidas por órganos de voluntad popular y que en caso de desconocerlas existe una autoridad que le obliga a hacerlo y le impone una sanción por dejar de hacerlo. Claramente señala Santofimio Gamboa (2003): "En su relación con la función administrativa del Estado, el principio de legalidad de los actos administrativos surge igualmente, de manera simultánea, con la institucionalización del poder" (p. 39). Se trata de la aplicación del principio de legalidad que está presente antes de la existencia de todo acto por cualquiera de los órganos del poder público.

El principio de legalidad, así contemplado en Colombia, es la columna que estructura el funcionamiento de la administración pública. Santofimio Gamboa (2003) dice que el principio de legalidad debe entenderse como la "necesaria conformidad de sus actos con el ordenamiento jurídico en general, y con el que le da fundamentación en especial" (p. 41). Sin embargo, dice este autor que la Administración se ciñe a la legalidad al guiar sus actuaciones por los preceptos 
García, W., y Bedoya, O. El debido proceso en la liquidación de revisión...

superiores como la Constitución y la ley, pero además a las elaboraciones interpretativas de la jurisprudencia y que constituyen precedente.

De conformidad con estos lineamientos se analiza el asunto planteado.

\section{El debido proceso constitucionalmente considerado}

En el contexto constitucional colombiano, establece el artículo 29 de la Constitución Política de Colombia:

El debido proceso se aplicará a toda clase de actuaciones judiciales y administrativas. Nadie podrá ser juzgado sino conforme a las leyes preexistentes al acto que se le imputa, ante el juez o tribunal competente y con observancia de la plenitud de las formas de cada juicio (...).

Acorde con esta norma, se le define atendiendo al órgano que actúa, a la función que cumple y al procedimiento que debe desplegarse y como aquel que inicia y adelanta el funcionario competente, y en el que se deciden situaciones relacionadas particulares, respetando el derecho de defensa, de conformidad con las pruebas y respetando las formas procesales. Dice la Corte Constitucional:

El debido proceso comprende un conjunto de principios materiales y formales entre los que se encuentran el principio de legalidad (memo index sine lege), el principio del juez natural o juez legal, el principio de favorabilidad penal y el principio de presunción de inocencia, todos los cuales en estricto rigor responden mejor a la estructura jurídica de verdaderos derechos fundamentales. El art. 29 de la Carta contempla, además, otros derechos que se entienden. (Corte Constitucional, 1992)

Sobre el tema afirma Cardona J. (2012):

El debido proceso se posesiona [sic] en el ordenamiento jurídico colombiano como un derecho fundamental reconocido a la persona y como tal se le asigna un nivel reforzado de protección frente a las actuaciones de los poderes públicos. Así, se predica ese derecho prima facie de la persona con relación al Estado (dimensión subjetiva), destacándose que desde su estructura normativa tiene la condición de principio. (p. 225)

En virtud del debido proceso, las autoridades administrativas y judiciales deberán acatar las formalidades de cada procedimiento y garantizar que se apliquen las normas que autorizan la presentación de pruebas y la controversia de las existentes. El ciudadano podrá solicitar que se les reconozcan sus derechos y que pueda garantizarse el ejercicio efectivo del derecho de defensa.

Al respecto, la Corte determinó en la Sentencia C-214:

En esencia, el derecho al debido proceso tiene la función de defender y preservar el valor de la justicia reconocida en el preámbulo de la Carta Fundamental, como una garantía de la convivencia social de los integrantes de la comunidad nacional. (Corte Constitucional, 1994) 
Es claro, entonces, que el debido proceso deberá seguirse en todos los procedimientos de la administración.

\section{El debido proceso en actuaciones administrativas}

Ahora bien, en cuanto al proceso administrativo, el debido proceso se manifiesta afirmando su apego a los principios y derechos constitucionales garantizando la efectividad de estos, para dar cumplimiento al artículo 209 de la Constitución y servir a los intereses generales y a las autoridades administrativas que "deben coordinar sus actuaciones para el adecuado cumplimiento de los fines del Estado" (Artículo $2^{\circ}$ de la Carta).

En desarrollo de las normas constitucionales, en el capítulo I del Título I del Código de Procedimiento Administrativo y de lo Contencioso Administrativo C.P.A.C.A. se consagran los principios generales de las actuaciones administrativas, aplicables en todos los casos. Las autoridades deben interpretar y aplicar las normas administrativas, de acuerdo con los principios consagrados en la Constitución Política, en el propio Código Contencioso Administrativo y en normas especiales. Explícitamente se refiere al debido proceso el segundo inciso del artículo $3^{\circ}$ : "Las actuaciones administrativas se desarrollarán, especialmente, con arreglo a los principios del debido proceso, igualdad, imparcialidad, buena fe, moralidad, participación, responsabilidad, transparencia, publicidad, coordinación, eficacia, economía y celeridad”. En el numeral 1 del artículo se establece que en "En virtud del principio del debido proceso, las actuaciones administrativas se adelantarán de conformidad con las normas de procedimiento y competencia establecidas en la Constitución y la ley, con plena garantía de los derechos de representación, defensa y contradicción".

En materia administrativa sancionatoria, se observarán adicionalmente los principios de legalidad de las faltas y de las sanciones, de presunción de inocencia, de no reformatio in pejus y non bis in ídem. Se cumplirán también el principio de igualdad, imparcialidad, buena fe, publicidad, eficacia, economía y celeridad.

Como contrapartida, los administrados tienen la carga de observar y utilizar todos los medios procesales que la ley les ofrece para proteger y hacer efectivos sus derechos y su conducta omisiva, negligente o descuidada acarrea consecuencias jurídicas desfavorables para aquellos, así como la improcedencia de la acción de tutela para efectos de cuestionarlas.

\section{V.I. El principio de publicidad dentro del debido proceso administrativo}

Según la Carta Fundamental (artículos 29 y 209), el debido proceso administrativo impone la publicidad como principio rector de las actuaciones (artículo 209 C.P. y $3^{\circ}$ C.P.A.C.A.), de tal manera que la Administración está 
García, W., y Bedoya, O. El debido proceso en la liquidación de revisión...

obligada a dar a conocer a sus destinatarios aquellos actos que supongan una afectación directa de su situación jurídica.

Al respecto, afirmó la Corte Constitucional en la Sentencia C-096 de 2001:

El conocimiento de los actos administrativos, por parte del directamente afectado, no es una formalidad que pueda ser suplida de cualquier manera, sino un presupuesto de eficacia de la función pública administrativa - artículo 209 C.P.- y una condición para la existencia de la democracia participativa. (Corte Constitucional, 2001)

En desarrollo del principio de publicidad, la notificación de las decisiones asegura la legalidad de las determinaciones adoptadas y el uso efectivo de los derechos de defensa, de contradicción y de impugnación que el ordenamiento jurídico consagra.

Sobre las notificaciones precisa el Consejo de Estado

En cuanto al artículo 68 del C.P.A.C.A. que dispone sobre las notificaciones personales: si no hay un método más eficaz de notificación al interesado, podrá enviarse la citación "a la dirección sin formalidad alguna; y amplía las posibilidades de envío a un número de fax, a un correo electrónico o los datos que se puedan obtener del registro mercantil. (Consejo de Estado-Sala de Consulta y Servicio Civil, 2017)

Se trata de amplio margen para determinar el medio que sea más eficaz para citar al interesado con el propósito de llevar a cabo la notificación personal sin limitarlo a un medio o formalidad específica.

En dicho sentido, el artículo 103 de la Ley 2010 de 2019 al adicionar un inciso y parágrafo al final del artículo 563 del Estatuto Tributario, dispuso que la notificación de las actuaciones administrativas tributarias, de manera preferente se realizará a la dirección electrónica consignada por el responsable, agente retenedor y/o declarante en el Registro Único Tributario -RUT-. Por su parte el artículo 566-1 del Estatuto Tributario (modificado por el Artículo 105 de la citada Ley) establece el término de la notificación y se dan cinco días, a partir del recibo del correo electrónico, para que empiecen a correr los términos legales para responder o impugnar en sede administrativa.

La norma establece garantías para el contribuyente, responsable, agente retenedor y/o declarante, de tal manera que con la notificación electrónica no se impida su defensa. Es así como se establece en el artículo 566-1 que en el evento de que por razones tecnológicas no se pueda acceder al contenido del acto administrativo, el contribuyente, responsable, agente retenedor y/o declarante podrá comunicarlo a la DIAN dentro de los tres días siguientes a su recibo y esta deberá enviar nuevamente la notificación, sin perjuicio de que empiecen a correr los términos legales deberán transcurrir cinco días a partir del recibo del correo. Si no puede notificarse electrónicamente, por inconvenientes por parte de la administración o del contribuyente, se notificará el acto personalmente, de acuerdo con los artículos 565 y 568 del Estatuto Tributario. 
De acuerdo con estos lineamientos legales, la Dirección de Impuestos y Aduanas Nacionales emitió la Resolución 000038 del 30 de abril de 2020, donde determina que la notificación por medios electrónicos será el mecanismo preferente de notificación de las actuaciones en materia tributaria, aduanera o cambiaria. En términos generales este acto reglamentario también dispone que al administrado tributario se le remitirá a su dirección de correo electrónico los siguientes elementos: a) Código de verificación, que permita al administrado verificar la autenticidad del mensaje enviado. b) Nombre completo del Administrado, NIT, la fecha de expedición del mensaje y la indicación de los medios electrónicos complementarios para visualizar el acto administrativo y su contenido, en caso de existir. c) El acto administrativo adjunto, en su totalidad y, d) La advertencia que mediante el respectivo correo se está notificando el acto administrativo adjunto, los recursos que legalmente proceden, las autoridades ante quienes deben interponerse y los plazos para hacerlo (Artículo 5).

Disposición que también establece una presunción legal al entender que el administrado al consignar su correo electrónico en el RUT ha expresado su voluntad de ser notificado electrónicamente y por lo tanto adquiere unas obligaciones formales de suministrar información verídica y actualizada, responder por la seguridad de la dirección de correo electrónico, hacer uso adecuado de los códigos de verificación, al igual que revisar de manera periódica la bandeja de "comunicados" que tiene asignada la entidad en el Portal Transaccional (Artículo 9).

De acuerdo con un reciente fallo del Consejo de Estado (Consejo de EstadoSección Primera, 2016), faltando la notificación de un acto administrativo es inoponible e ineficaz frente a quienes lo desconocen. Esta posición se mantiene y así lo ha dispuesto el Consejo de Estado (Consejo de Estado- Sala de lo Contencioso Administrativo, 2018)

Sobre el tema, la Corte Constitucional se pronunció, haciendo referencia a la función triple de la notificación:

(i) asegura el cumplimiento del principio de publicidad de la función pública, dado que mediante ella se pone en conocimiento de los interesados el contenido de las decisiones de la Administración; (ii) garantiza el cumplimiento de las reglas del debido proceso en cuanto permite la posibilidad de ejercer los derechos de defensa y de contradicción; y (iii) la adecuada notificación hace posible la efectividad de los principios de celeridad y eficacia de la función pública al delimitar el momento en el que empiezan a correr los términos de los recursos y de las acciones procedente. (Corte Constitucional, 2014)

Es claro que la notificación es la comunicación al ciudadano por parte de la administración en la cual se le hace saber que se ha proferido un acto particular o que se ha iniciado un proceso que puede afectarle y que garantiza el principio 
García, W., y Bedoya, O. El debido proceso en la liquidación de revisión...

de contradicción y, en especial, prevenir que alguien pueda ser condenado sin ser oído. Define, además, la oponibilidad de los actos de la Administración.

\section{V.II. Los medios de prueba}

La Corte Constitucional en reiteradas ocasiones se ha referido al derecho a la prueba como componente del debido proceso y del derecho a la administración de justicia y manera de alcanzar la verdad en una investigación judicial. Sobre el tema pueden referenciarse las sentencias de la Corte Constitucional T-589 de 1999, (Corte Constitucional, 1999) y T-171 de 2006, (Corte Constitucional, 2006).

Este contexto obliga a analizar desde el derecho constitucional enfocado hacia el derecho administrativo, la relación entre debido proceso y prueba. Muestra de eso es lo establecido en el artículo 40 de la Ley 1437 de 2011 (C.P.A.CA) que preceptúa que toda actuación del Estado (función pública) se deberá soportar en acervo probatorio, bien sea, solicitado por el administrado o decretadas de oficio por la entidad.

En el caso concreto de la función pública desplegada en materia tributaria, la DIAN en razón de legalidad de la prueba y garantía del debido proceso en sí, podrá hacer uso de los actos preparatorios como lo son el requerimiento de información y el auto de inspección contable y tributaria que contemplan los artículos 779 y 782 del Estatuto Tributario. El interesado contará con la oportunidad de controvertir las pruebas aportadas o practicadas dentro de la actuación, antes de que se dicte una decisión de fondo. Es menester resaltar que dicha decisión que decreta medios probatorios no son objetos de recursos.

En la Sentencia C-034, la Corte Constitucional (2014), precisó que no era posible afirmar la identidad entre el proceso judicial y el proceso administrativo, puesto que este se rige por principios rectores que garantizan el debido proceso y, además, por los principios que definen la función pública, regida por principios de igualdad, moralidad, eficacia, economía, celeridad, imparcialidad y publicidad.

\section{V.II.I. El derecho a aportar y controvertir las pruebas}

Este derecho lo define la Corte Constitucional en la Sentencia C-034 de 2014 como el medio para que el funcionario administrativo obtenga el conocimiento necesario de los hechos, aplique las normas jurídicas pertinentes y dé respuesta a los asuntos que están bajo su competencia.

La estructura probatoria es una parte esencial de los procedimientos administrativos y comprende las oportunidades para solicitarlas, la atribución del juez para decretarlas y practicarlas, la facultad para producir pruebas de oficio y las reglas que deben seguirse para su valoración. 


\section{VI.El debido proceso administrativo tributario}

El principio constitucional del debido proceso en materia tributaria significa que este debe realizarse de conformidad con las normas existentes al momento de ocurrir el proceso, ante el funcionario competente y bajo el estricto cumplimiento de todas las formalidades que la propia ley establece y se aplica a todas las investigaciones adelantadas por las autoridades tributarias. Galvis A. (2019) recoge en la caracterización del debido proceso tributario su distintivo constitucional:

El procedimiento tributario, al garantizar el debido proceso, brinda el derecho de defensa de los contribuyentes u obligados a cumplir las obligaciones tributarias. Para tal efecto, ha de otorgar la posibilidad de controvertir todos los actos administrativos, sean definitivos o de trámite, llámense requerimientos especiales o liquidaciones oficiales, pliegos de cargos o resoluciones. Además, los contribuyentes pueden aportar pruebas, solicitar revisiones especiales e inspecciones contables o tributarias para aclarar los hechos en la oportunidad y dentro del término debido (Galvis A., 2019, p. 124).

Teniendo en cuenta que uno de los procesos a que da lugar la función tributaria del Estado es la Liquidación Oficial de Revisión, y que se pretende abordar desde la garantía del debido proceso, se hace imperioso el procedimiento de discusión del impuesto, los actos administrativos que pueden emitirse por la DIAN y los recursos existentes contra dichos actos.

Es así como una vez presentada la declaración tributaria, la DIAN, de conformidad con el artículo 705 del Estatuto Tributario, deberá notificar el requerimiento del artículo 703 ibídem, a más tardar dentro de los tres años siguientes a la fecha del vencimiento del plazo para declarar, teniendo en cuenta que, en los casos de la declaración extemporánea, el plazo comienza a contarse a partir de la fecha de presentación de la misma. En el evento de que la declaración tributaria presente un saldo a favor, el plazo de los tres años se cuenta después de la fecha de presentación de la solicitud de devolución o compensación.

Entonces se tiene que el referenciado requerimiento especial como preparatorio tiene como fin proponer al contribuyente que modifique la liquidación privada, explicando las razones en que se fundamenta y dentro del término de los tres años siguientes al plazo para declarar.

Conforme a las facultades de fiscalización e investigación que cuenta la DIAN y que son atribuidas por el artículo 684 del Estatuto Tributario, podrá, antes del requerimiento especial, proferir un requerimiento ordinario y luego expedir el acto administrativo de liquidación de revisión, con miras a recaudar información que permita determinar la veracidad o no de la información. 
García, W., y Bedoya, O. El debido proceso en la liquidación de revisión...

En caso de que no lo sea, este acervo probatorio será fundamento del requerimiento especial.

En esta etapa la DIAN podrá cruzar información mediante la verificación con terceros y solicitar información adicional. Es así como podrá:

a) verificar la exactitud de las declaraciones o informes, si lo considera necesario;

b) adelantar investigaciones que le permitan establecer la generación de hechos generadores de obligaciones tributarias y que no se hayan declarado;

c) podrá exigirle al contribuyente o a terceros que presenten documentos que registren operaciones y cuando ambos estén obligados a llevar libros registrados;

d) ordenar la exhibición de libros, comprobantes y documentos del contribuyente o de terceros, estando obligados a llevar contabilidad;

e) efectuar diligencias que sean necesarias para determinar correcta y oportunamente los impuestos, facilitando al contribuyente que aclare dudas y omisiones para lograr una correcta determinación;

f) La DIAN, para fines fiscales, cuenta con plenas facultades de revisión y verificación de los estados financieros, "sus elementos, sus sistemas de reconocimiento y medición, y sus soportes, los cuales han servido como base para la determinación de los tributos". Igualmente, de conformidad con el artículo 275 de la Ley citada, puede solicitar la transmisión electrónica de la contabilidad, de los estados financieros y demás informes, los cuales constituirán prueba en este tipo de investigación.

El requerimiento especial deberá notificarse al contribuyente, responsable, agente retenedor y/o declarante para que en un plazo de tres meses (prorrogable por la administración hasta por otros 3 meses en caso de nuevos hechos a investigar) se formule por escrito las objeciones, aportar y solicitar pruebas.

La DIAN dentro de los seis meses siguientes al vencimiento del plazo para dar respuesta al requerimiento, podrá notificar la liquidación oficial de revisión, salvo que se requiera realizar inspección tributaria, que se suspenderá dicho plazo hasta por tres meses, tal como lo dispone el artículo 710 del Estatuto Tributario.

Teniendo en cuenta la información recibida, la DIAN profiere el acto administrativo que contiene la liquidación de revisión y las sanciones -bien sea por corrección, por inexactitud y los correspondientes intereses moratorios- que fueren del caso y es por ello que se conoce en la doctrina como "resolución-sanción" que debe notificarse en la forma establecida por la Ley, y que es objeto del recurso de reconsideración, el cual puede interponerse o no por el contribuyente, responsable, agente retenedor y/o declarante dentro de los dos meses siguientes a su notificación. No se considera como obligatorio entablar la acción de nulidad y restablecimiento del derecho ante la jurisdicción 
contenciosa administrativa que deberá presentarse dentro de los cuatro meses siguientes a la firmeza de la liquidación (Literal d, numeral $2^{\circ}$ del artículo 164 de la Ley 1437 de 2011 y parágrafo del artículo 720 del Estatuto Tributario).

A grosso modo se ha presentado el proceso administrativo sancionatorio tributario para el caso de la liquidación oficial de revisión, sin antes advertir que se establece en favor del contribuyente, responsable, agente retenedor $\mathrm{y} / \mathrm{o}$ declarante, y como garantía del debido proceso, una serie de oportunidades para acreditar que los datos aportados y con los cuales justificó su declaración se ajustan a las normas tributarias; también existe una serie de términos que se deben respetar con sigilo a fin de no perder la oportunidad procesal de defender sus intereses o que en caso de que la administración no lo respete, pierda su competencia para impartir sanciones y se tenga que terminar el procedimiento a favor del administrado.

\section{VI.I. La Liquidación Oficial de Revisión, en tanto se trata de un acto administrativo, deberá ajustarse al principio de legalidad}

Para comprender el significado constitucional y legal de la liquidación oficial de revisión, hay que precisar que esta hace parte del poder tributario que según Piza (2008) se deriva de las normas básicas contempladas en el título XII de la Constitución Política de 1991, que establecen el marco jurídico de la actividad económica de los actores públicos y privados, en lo relativo a "la propiedad privada, principios como la libertad de empresa y la economía de mercado, así como el régimen de intervención de los poderes públicos en la actividad económica privada" (p. 53). Una de las esferas principales de intervención del Estado en la economía comprende el poder fiscal referido a la atención del gasto público que comprende el poder tributario.

Ahora bien, en el contexto constitucional colombiano se incluyen preceptos que establecen el poder fiscal en cabeza del Estado, y lo caracteriza como la facultad de creación de tributos regida por el principio de legalidad; es decir, significa que solo es la ley la que puede establecerlos, tal como está escrito en los artículos 150 y 388 de la Constitución Política. En su aplicación es el propio Estado quien debe recaudarlos, acatando siempre los principios que la propia ley consagra y los derechos que concierne a los ciudadanos.

El poder tributario, según Piza (2008), ha sido claramente delimitado con el fin de evitar intromisiones indebidas del Estado en la actividad económica, lo cual constituye un principio democrático del Estado Social de derecho. Pero, al mismo tiempo, esa libertad económica y la garantía para los ciudadanos están sometidas a la limitación constitucional que implica la obligación de contribuir al financiamiento de los gastos e inversiones del Estado, como lo establece el artículo 95 de la Constitución. 
García, W., y Bedoya, O. El debido proceso en la liquidación de revisión...

Para que el Estado ejerza su potestad tributaria se autoriza al máximo órgano de lo fiscal, la DIAN, para exigirle al ciudadano que le haga conocer su actividad económica y los resultados de esta mediante una declaración formalizada ante dicha autoridad, al tiempo que debe respetar sus derechos tanto en relación al contenido como al procedimiento para brindarla.

Como garantía de los derechos tributarios, como afirma Piza (2014), una de las notas características del procedimiento es la consagración de la autoliquidación de impuestos como el de Renta, el IVA, la retención en la fuente. Así, al tiempo que se eliminó la intromisión del Estado por medio de funcionarios que determinaban la liquidación respectiva, se impusieron al contribuyente y al agente de retención las obligaciones de: declarar el monto sobre el cual debe hacerlo, la aplicación de la tarifa, la imputación de retenciones, anticipos y saldos, sanciones y el monto a pagar con los intereses respectivos (p. 245).

Sin embargo, aunque el Estado no interviene en la declaración y liquidación, reserva su poder para fiscalizar y determinar que estas se realicen de conformidad con los hechos que atañen a cada contribuyente y agente de retención y con las normas establecidas para el cobro de los tributos.

En este ámbito, las normas tributarias han consagrado la figura jurídica de la liquidación oficial de revisión como aquella donde se determinan impuestos, anticipos y retenciones "a partir de una modificación de las bases gravables y de la depuración tributaria incorporada en una respectiva declaración, acorde con el desarrollo fáctico y jurídico recabado en el acto administrativo preparatorio" (Cermeño, De Bedout, Andrés y Clopatofsky, 2017). En esta liquidación se imponen las sanciones por inexactitud.

Esta modalidad de liquidación, expresión del poder de fiscalización de la administración, debe contener unos requisitos legales, tal como se establece en los artículos 702 y siguientes del estatuto tributario, entre ellos, el requerimiento especial contemplado en el artículo 703 que establece que:

Antes de efectuar la liquidación de revisión, la Administración enviará al contribuyente, responsable, agente retenedor o declarante, por una sola vez, un requerimiento especial que contenga todos los puntos que se proponga modificar, con explicación de las razones en que se sustenta.

La liquidación deberá estar suficientemente sustentada, utilizando la explicación jurídica y fáctica, fundada en las pruebas que se someten al principio de contradicción como lo establece el artículo 742 del Estatuto Tributario. Como todo acto administrativo podrá incurrir en defectos que la vicien de nulidad, la cual podrá proponerse en sede administrativa, mediante el recurso de reconsideración.

La naturaleza jurídica de la liquidación de revisión es la de un título ejecutivo que contiene una obligación clara, líquida y exigible por la administración y da 
lugar al cobro coactivo, mediante el respectivo proceso, para exigir el pago de las sumas ordenadas. Deberá provenir de una autoridad administrativa competente, en este caso el jefe de la unidad de liquidación de cada dirección seccional de la DIAN, quien puede delegar en funcionarios a su cargo la realización de los estudios y verificaciones y la práctica de pruebas encaminadas a sustentar "la determinación oficial de un tributo a cargo de un contribuyente, responsable, agente de retención o declarante, que hubiera sido liquidado en forma indebida por parte del obligado" (Cermeño et al., 2017, p. 180). La liquidación se notificará de acuerdo con lo dispuesto en el artículo 565 del Estatuto Truibutario, en forma electrónica, personal o por la red de correos oficiales o servicio de mensajería autorizado, tal como se especificó en líneas anteriores cuando se hizo referencia a los artículos 103 y 105 de la Ley 2010 de 2019.

La oportunidad procesal para la notificación de la liquidación oficial será dentro de los seis meses posteriores a la fecha del vencimiento del plazo para responder el requerimiento especial o su ampliación, no obstante que el contribuyente, responsable, agente retenedor, dé respuesta al requerimiento especial. El término establecido puede suspenderse en dos casos especiales, de conformidad con el artículo 710 del Estatuto Tributario:

Cuando se practique inspección tributaria de oficio, el término anterior se suspenderá por el término de tres (3) meses contados a partir de la notificación del auto que la decrete.

Cuando se practique inspección contable a solicitud del contribuyente, responsable, agente retenedor o declarante el término se suspenderá mientras dure la inspección.

Cuando la prueba solicitada se refiera a documentos que no reposen en el respectivo expediente, el término se suspenderá durante dos meses.

La liquidación de revisión, respetando el derecho de defensa y el debido proceso, restringirá el contenido de esta a la declaración del contribuyente. Tendrá en cuenta los presupuestos fácticos y los efectos jurídicos de la misma. Este punto es importante, porque hacerlo de otra manera imposibilitaría al contribuyente para fundamentar los argumentos encaminados a destruir la argumentación de la autoridad tributaria. Cermeño et al. (2017) citan sentencias del Consejo de Estado en las cuales se especifica que violar el principio de correspondencia equivale a desconocer el debido proceso:

Consejo de Estado, Sección Cuarta, Sentencias del 6 de octubre de 2005, Exp. 14635, C. P. Ligia López Díaz, del 18 de junio de 2009,Exp. 15540, C.P. Héctor romero, del 16 de octubre de 2014, Exp. 18752, C.P. Jorge Octavio Ramírez, del 23 de septiembre de 2013, del $1^{\circ}$ de agosto de 2013, Exp. 18861, C.P. Carmen Teresa Ortiz, del 25 de junio de 2012, Exp. 17844, C..P. Carmen Teresa Ortiz, y del 2 de febrero de 2012, Exp. 16760 C.P. Hugo Fernando Bastidas, entre otras. (p. 184) 
García, W., y Bedoya, O. El debido proceso en la liquidación de revisión...

Aunque el artículo 712 del Estatuto Tributario no contempla la inclusión del material probatorio dentro del contenido de la liquidación de revisión, este deberá hacer parte de él, para que el contribuyente, bien sea el responsable del IVA, el agente de retención o el declarante, tenga conocimiento de ella y pueda controvertirlo. Es esta una obligación de la administración y un derecho del contribuyente que garantiza el debido proceso y que tiene fundamento en el artículo 742 del Estatuto Tributario que establece:

La determinación de tributos y la imposición de sanciones deben fundarse en los hechos que aparezcan demostrados en el respectivo expediente, por los medios de prueba señalados en las leyes tributarias o en el Código de Procedimiento Civil, en cuanto éstos sean compatibles con aquellos.

Como decisión en derecho que pone fin a una actuación de la Administración, la liquidación de revisión es susceptible de recursos por la vía administrativa y judicial. En sede administrativa, puede impugnarse mediante el recurso de reconsideración, a no ser que el contribuyente, responsable, agente de retención o declarante, opte por aceptar la determinación tomada por la Administración o demande judicialmente la liquidación. Hay que anotar que la interposición del recurso de reconsideración no constituye un requisito para entablar la demanda ante la jurisdicción de lo contencioso administrativo, cuando el contribuyente ha atendido en debida forma el requerimiento especial. Así lo ha determinado la jurisprudencia del Consejo de Estado, como efectivamente lo hizo en las sentencias:

Sentencias de 10 de octubre de 2007, Exp. 15134 y de 10 de abril de 2008, Exp. 2002-00823 [15857], entre otras. Autos de 27 de mayo de 2004, Exp. 14348, y de 11 de noviembre de 2004, Exp. 14347, entre otros. Sentencia del 12 de diciembre de 2006, expediente 14826, CP. Ligia López Díaz reiterada en sentencia de 12 de mayo de 2010, Exp. 16448 M.P. Dr. Hugo Fernando Bastidas Bárcenas., acogidas en la Sentencia del 8 de septiembre de 2017 (Consejo de Estado. Sala de lo Contencioso Administrativo [Magistrada ponente: Stella Jeannette Carvajal Basto], 8 de septiembre de 2017)

Ahora bien, el recurso de reconsideración debe interponerse dentro de los dos meses siguientes a la notificación de la liquidación de revisión, de conformidad con el artículo 720 del Estatuto Tributario y el término se cuenta desde el día de la expedición del acto. Cuando la ley habla "meses" se trata de meses del calendario, salvo que el día final del segundo mes sea festivo.

La competencia para resolver el recurso la fija el artículo 720: deberá presentarse ante la oficina competente para conocer los recursos tributarios de la Administración que expidió el acto respectivo y cuando el acto se profiere por el Administrador de impuestos o su delegado, el recurso de reconsideración debe interponerse ante el mismo funcionario que lo profirió. La admisión del recurso se hará dentro del mes siguiente y deberá notificarse por correo al interesado. El recurso puede inadmitirse mediante un auto expedido por el funcionario ante 
quien se interpuso. Si se exigen requisitos pueden subsanarse dentro de los diez días siguientes o invocar el recurso de reposición, que se resolverá dentro de los cinco días siguientes, pues de lo contrario opera el silencio administrativo positivo y se entiende que fue admitido.

En el artículo 730 del Estatuto Tributario se establecen las causales de nulidad de los actos administrativos y, por lo tanto, los actos de liquidación de impuestos y resolución de recursos son nulos:

1. Cuando se practiquen por funcionario incompetente.

2. Cuando se omita el requerimiento especial previo a la liquidación de revisión o se pretermita el término señalado para la respuesta, conforme a lo previsto en la ley, en tributos que se determinan con base en declaraciones periódicas.

3. Cuando no se notifiquen dentro del término legal.

4. Cuando se omitan las bases gravables, el monto de los tributos o la explicación de las modificaciones efectuadas respecto de la declaración, o de los fundamentos del aforo.

5. Cuando correspondan a procedimientos legalmente concluidos.

6. Cuando adolezcan de otros vicios procedimentales, expresamente señalados por la ley como causal de nulidad.

El artículo 137 del Código de Procedimiento Administrativo y de lo Contencioso Administrativo contempla seis causales de nulidad de los actos administrativos:

i) Sean expedidos con infracción de las normas en que debía fundarse

ii) Sean proferidos por un funcionario incompetente

iii) Sean promulgados en forma irregular, sin observancia de los procedimientos establecidos para ello,

iv) Sean expedidos con desconocimiento del derecho de defensa y contradicción de un contribuyente, responsable, agente de retención o declarante,

v) Sean proferidos a partir del sustento de una falsa motivación y/o sean promulgados a partir de una desviación de las atribuciones propias de quien los profirió.

Cuando el acto haya sido proferido por el Administrador de Impuestos o sus delegados, el recurso de reconsideración deberá interponerse ante el mismo funcionario que lo profirió.

\section{VI.II. Las indagaciones en que se apoya la liquidación de revisión}

La fiscalización por la Administración tiene como objetivo examinar las declaraciones y las autoliquidaciones de las personas naturales y jurídicas obligadas a tributar de conformidad con la ley; la facultad incluye la capacidad y la competencia para investigar lo que se ha ocultado o se ha afirmado falsamente. Las funciones de fiscalización se enumeran en el artículo 684 del 
García, W., y Bedoya, O. El debido proceso en la liquidación de revisión...

Estatuto tributario que, según Piza (2014), consisten en comprobar lo declarado e investigar lo no declarado para proferir el acto administrativo, para lo cual se requieren actos preparatorios necesarios para ello.

La naturaleza jurídica de la fiscalización es la de una función inquisitiva orientada a establecer y documentar las averiguaciones y establecer probatoriamente si un contribuyente, responsable, agente retenedor o declarante ha desconocido las normas, evadiendo o eludiendo las obligaciones tributarias.

Piza (2014) caracteriza la función de fiscalización:

Para el cabal ejercicio de esta función, la administración debe adelantar actividades que en principio implican la comprobación de valores, pero que bien entendidas también comprenden la valoración del proceso de aplicación de las normas efectuado por el contribuyente objeto de la revisión. Bajo esta expresiónaplicación- se engloban todas las actividades que implica el juicio de determinación de consecuencias jurídicas, a saber: la calificación de los hechos, la interpretación de las normas seleccionadas como aplicables al caso y la subsunción de los hechos calificados — premisa menor - en la interpretación efectuada de dichas normas premisa mayor-, para así atribuirle una consecuencia jurídica tributaria a la situación fáctica valorada. Igualmente, en el curso de la fiscalización la administración debe establecer si los obligados tributarios han incurrido en conductas tipificadas como infracciones tributarias, investigación punitiva con la cual, si es el caso, se da inicio al procedimiento administrativo sancionador. (p. 234)

$Y$ es que el poder tributario está subordinado al derecho, como bien lo expresa Piza (2008). Se ha visto que el procedimiento para la expedición de la liquidación de revisión tiene contempladas todas las etapas con los diversos requisitos que es obligatorio cumplir en cada una de ellas. En lo no determinado hay remisión expresa a las normas del Código de Procedimiento Administrativo y Contencioso Administrativo.

Hay un tema importante: previamente al requerimiento a un contribuyente, responsable, agente de retención o declarante, es necesario que existan algunos indicios o evidencias de que los datos consignados en la declaración o en la liquidación no se ajustan a los hechos económicos o a las normas legales y son estos los que activan la facultad de fiscalización por parte de la administración y se practican las pruebas necesarias para confirmar o desestimar las sospechas o conjeturas existentes.

Piza (2008) al referirse a esta facultad se remite a la Constitución de 1991 que incorporó principios al derecho tributario, tales como: eficiencia, equidad y progresividad, que orientan el deber de los ciudadanos de contribuir al financiamiento de los gastos del Estado y que impiden la afectación de los derechos ciudadanos. La eficiencia se considera como un principio que opera cuando se trata de atacar prácticas como la evasión y la elusión; la Corte Constitucional la avala en casos de sanciones administrativas y penales. El alto 
organismo relaciona la eficiencia con el Estado Social de Derecho y con su obligación de cumplir eficazmente sus propósitos.

En lo que tiene que ver con la equidad, la progresividad y la igualdad, se trata de principios que se relacionan con el reparto de la carga tributaria y pretenden que los aportes económicos estén en relación con la capacidad de las personas, limitación al poder tributario.

A este tema se refieren algunos autores (Romero-Molina, GrassSuárez y García-Caicedo, 2013) quienes argumentan, apoyados en normas constitucionales, que existen unos límites a lo que denominan la "arbitrariedad impositiva" (p. 67) y que enuncian así: i) principio de legalidad tributaria, que protege la seguridad jurídica y la limitación del poder impositivo del Estado; ii) Principios de equidad, eficiencia y progresividad del tributo contemplados en el artículo 363 de la Constitución Política (que establece: "El sistema tributario se funda en los principios de equidad, eficiencia y progresividad") iii). Principio de igualdad tributaria que está asociado a los principios de equidad, progresividad y capacidad de pago y en virtud de él busca evitar arbitrariedades y afirman: "Estos principios tributarios consagran el límite impuesto al Estado en relación con la actuación tributaria”. (p. 70). Este último considera la diferencia social entre los habitantes del Estado colombiano; va de la mano con los principios de equidad, progresividad y capacidad de pago; busca poner un límite al poder del Estado y así evitar arbitrariedades. En cuanto a la irretroactividad, es claro su efecto hacia el futuro y a la generalidad que las normas operan para todos.

La Corte Constitucional se refiere a los principios de igualdad, equidad y justicia tributaria en las relaciones Estado-ciudadano:

Del principio de igualdad se deriva "un mandato de igualdad formal ante la ley, según el cual todas las personas que compartan la misma situación merecen ser tratadas de la misma manera, mientras que aquellas que se encuentren en situaciones que presenten diferencias constitucionalmente relevantes, deben ser tratadas de manera diferente, siempre y cuando ello no comporte discriminación injustificada por razones de sexo, raza, origen nacional o familiar, lengua, religión, opinión política o filosófica. Asimismo, incorpora un mandato de igualdad material, que ordena al Estado promover las condiciones para que la igualdad sea real y efectiva, adoptando medidas en favor de grupos discriminados o marginados.” (Corte Constitucional, 2018)

La equidad tributaria es un criterio con base en el cual se pondera la distribución de las cargas y de los beneficios o la imposición de gravámenes entre los contribuyentes para evitar que haya cargas excesivas o beneficios exagerados. Una carga es excesiva o un beneficio es exagerado cuando no consulta la capacidad económica de los sujetos pasivos en razón a la naturaleza y fines del impuesto en cuestión.

La justicia tributaria ha sido interpretada como una síntesis de todas las exigencias constitucionales que enmarcan el ejercicio del poder impositivo 
García, W., y Bedoya, O. El debido proceso en la liquidación de revisión...

del Estado (CP art 95-9). Además de incorporar las exigencias de equidad y progresividad antes mencionadas, también reclama un sistema tributario eficiente, capaz de asegurar un efectivo control de la recaudación de los dineros públicos. Así pues, al lado de la equidad y la progresividad, la eficiencia también constituye un componente medular de la justicia tributaria, dado que la ineficiencia en el recaudo de los tributos puede generar una injusta distribución de la carga fiscal, en tanto el incumplimiento de sus obligaciones impositivas por parte de algunos contribuyentes conduce a que el sostenimiento de los gastos e inversiones públicas solo se haga a costa de los contribuyentes cumplidos. A estos principios también se ha referido la Corte en la Sentencia C-600 de 2015 (Corte Constitucional, 2015).

Otro de los límites al poder de fiscalización es el de los derechos fundamentales que constituyen un límite no solo al poder legislativo de implementación de medidas para combatir la evasión y la inclusión, sino a la potestad de fiscalización. Piza (2008) menciona derechos fundamentales como la intimidad. Pero considera que la presentación de libros de contabilidad y demás documentos privados, en los términos legales, no constituye de por sí violación.

Dice Piza (2008), refiriéndose a la jurisprudencia que esta ha conciliado el alcance de las facultades de fiscalización con el derecho a la igualdad, definiendo que es legalmente que se determina la facultad de intervenir en el derecho a la intimidad, así como el alcance de la competencia y cuándo y en qué condiciones puede ejercerse, de conformidad con el artículo 684 del Estatuto Tributario que fija taxativamente dichas facultades amplias de fiscalización e investigación y que le permiten, verificar la exactitud de la información, investigar la ocurrencia de hechos generadores de obligaciones, citar o requerir al contribuyente para que informe o conteste interrogatorio, exigir la presentación de documentos, ordenar la exhibición de libros, comprobantes, documentos y realizar diligencias para determinar impuestos.

A este artículo se le adicionó un literal en cuanto a la facultad de la DIAN de revisar y verificar estados financieros que hayan servido para determinar los tributos. Se le adicionó, también, un parágrafo que dispone la posibilidad de solicitar la transmisión electrónica de la información contable, de acuerdo con las especificaciones técnicas, informáticas y de seguridad que establezca la dirección de la DIAN.

La información que se solicita debe ser necesaria y útil para efectos tributarios, y deberá conservarse debidamente sin divulgarse o utilizarse para fines distintos de los autorizados por la Constitución y las leyes; esta responsabilidad es extensiva a bancos, puesto que intervienen en la gestión tributaria. Los registros a oficinas, establecimientos comerciales, industriales o de servicios, locales del contribuyente o de terceros depositarios de documentos contables y archivos pueden realizarse por la DIAN. Otro tanto 
se ha dicho de las facultades de la administración de impuestos para efectuar registros de oficinas, establecimientos comerciales, industriales o de servicios y demás locales del contribuyente o responsable, o de terceros depositarios de documentos contables o sus archivos. Está excluida la revisión de la casa de habitación de los contribuyentes o de terceros (Piza, 2014).

\section{VI.III. Otras funciones de la fiscalización}

Además de las funciones anteriores orientadas a identificar los hechos generadores del impuesto, existe, además, la potestad para revisar la aplicación de las normas que el contribuyente ha hecho en su caso y confirmarla o modificarla. En concepto de Piza (2014) es esta la esencia de dicha facultad:

[...] la administración puede discrepar de dicha calificación y proponer su propia aplicación, que puede derivar de hechos nuevos no declarados, o de interpretaciones distintas de la norma, que en cualquiera de los dos eventos da lugar a una mayor deuda tributaria de la declarada por el contribuyente". (p. 246)

Zornosa y Muñoz (2010, citados por Piza, 2014) afirman; "la aplicación comprende la calificación del hecho, la interpretación de la norma y la subsunción del hecho concreto del contribuyente a la correspondiente norma"

Esta función constituye un tema complejo, pues se trata de un ámbito en el cual existe una gran inseguridad para el contribuyente, puesto que puede dar lugar al desconocimiento de sus derechos, y donde él no puede intervenir, ni solicitar la garantía constitucional debido a que se trata precisamente de interpretaciones que pueden albergar cierto margen de subjetividad, lo que evidenciaría una tensión entre facultades de la administración tributaria y las garantías del ciudadano.

Al respecto, Piza (2014) destaca que la Corte Constitucional en la Sentencia T-381 de 1993 manifestó:

[...] las actuaciones de la administración tributaria están gobernadas, como todo trámite que pueda culminar en la imposición de sanciones, por las reglas propias del debido proceso. En consecuencia, por perentorio e ineludible mandato del artículo 29 de la Carta, el contribuyente debe contar con oportunidad de defensa y tener a su alcance las opciones de probar, controvertir pruebas en su contra y ejercer los recursos pertinentes para atacar las determinaciones que lo afectan". [...] el Estado no puede ser privado de su poder de indagación tributaria ni de su capacidad investigativa, las cuales por ser de orden público, prevalecen sobre la voluntad de los particulares y se imponen a ellos.

\section{VI.IV. Algunos fallos recientes sobre el debido proceso}

En el proceso ante el Consejo de Estado dentro del proceso de Nulidad y Restablecimiento del Derecho, no se aceptó la nulidad por considerar que las pruebas omitidas no eran pertinentes ni conducentes. En la sentencia que se reitera, la Sala precisó que, de la interpretación del artículo 568 ib., se concluye, 
García, W., y Bedoya, O. El debido proceso en la liquidación de revisión...

que si la administración tributaria envía el acto objeto de notificación por correo a la dirección informada por el contribuyente en el RUT, o a la dirección procesal reportada en la actuación administrativa, o a la del apoderado registrada en el RUT, cuando se actúa a través de este, y la empresa oficial de correos o la empresa de mensajería especializada devuelve el correo por una razón distinta a la de dirección errada, la autoridad tributaria debe proceder a hacer la notificación por aviso, antes en un periódico de circulación nacional, actualmente en el portal web de la DIAN. En estos casos, la:

[...] notificación se entenderá surtida para efectos de los términos de la administración, en la primera fecha de introducción al correo, pero para el contribuyente, el término para responder o impugnar se contará desde el día hábil siguiente, a la publicación del aviso o de la corrección de la notificación. (Consejo de Estado, 2018)

Igualmente, el Consejo de Estado, a través de la Sala de lo Contencioso Administrativo, Sección Cuarta dispuso:

De la interpretación sistemática de las anteriores disposiciones, la Sala ha concluido el artículo 689 ibídem no limita el ejercicio de las facultades de investigación y fiscalización que desarrolla el artículo 684 del Estatuto Tributario. Esto, por cuanto, independientemente de que la declaración cobijada con el beneficio de auditoría pueda ser seleccionada por un programa de computador para su investigación, no la excluye del control fiscal que ejerce la DIAN, pues la Administración cuenta con amplias facultades para adelantar las investigaciones que estime conveniente y establecer la ocurrencia de hechos generadores de la obligación tributaria. (Consejo de Estado- Sala de lo Contencioso Administrativo, 2018)

Igualmente se afirmó con relación a los indicios:

La DIAN puede establecer por este medio la inexistencia de operaciones declaradas por el contribuyente o el responsable, puesto que un indicio implica la existencia de un hecho conocido, ya probado, del cual se deduce el hecho indicador y la adecuación lógica entre ellos. Y el indicio no reemplaza el hecho a corroborar, sino que es el punto inicial para razonar y demostrar el hecho que se debe comprobar.

En lo que tiene que ver la validez probatoria de los indicios, esta depende de la conducencia en relación con el hecho investigado y que se perfecciona cuando otros medios probatorios los ratifican.
VI.V. Un asunto a considerar: responsabilidad objetiva del contribuyente, el responsable del IVA o el agente retenedor y el respeto por la presunción de inocencia, pilar del debido proceso en materia sancionatoria.

Todo lo expuesto en las anteriores líneas, ha suscitado interrogantes acerca de si está consagrada la responsabilidad objetiva para los casos que dan lugar a la referida actuación de la administración, y si esta pueda ser un camino para 
que se desconozcan los derechos que amparan al contribuyente, al responsable del IVA y al agente retenedor.

Pensando este asunto de manera general, dicha liquidación erige determinados hechos en prueba de que los sujetos tributarios han incurrido en conductas que imponen un incremento de los tributos y las sanciones respectivas, es decir, no rige el principio de inocencia, sino el de culpabilidad, en tanto obliga a los sujetos pasivos a recolectar y a allegar el material con el cual pueden desvirtuar la sospecha de la administración, contrariamente al sistema penal en el cual es el Estado el que deberá desvirtuar el principio de inocencia que ampara a la persona imputada o acusada.

Es un tema importante y es que, previamente al requerimiento a un contribuyente, agente de retención o declarante, es necesaria la existencia de indicios o evidencias de que los datos consignados en la declaración o en la liquidación no se ajustan a los hechos económicos o a las normas legales. Es entonces cuando se activa la facultad de fiscalización por parte de la administración y se practican las pruebas necesarias para confirmar o desestimar las sospechas o conjeturas existentes. Y es la propia administración la que debería probar todos los hechos y no el particular demostrar "su inocencia tributaria".

El cuestionamiento y crítica al sistema impuesto se ha hecho por algunos autores y en sus planteamientos se apoya el reparo a la ausencia de garantía que implica el hecho de que sea el contribuyente quien debe probar su inocencia y no que la administración pruebe la culpabilidad, desvirtuando de esta manera el principio de inocencia que ampara al ciudadano en el derecho penal. Entre los autores, se encuentra Galvis Arteaga (2019), quien afirma que tanto la Corte Constitucional como el Consejo de Estado coinciden en su consideración de que no puede determinarse la responsabilidad del administrado con la certeza de la realización del hecho constitutivo de una infracción en materia tributaria. Sin embargo, su afirmación pierde firmeza, en tanto dice que las últimas sentencias no son "lo suficientemente constantes para establecer una línea jurisprudencial fuerte" (p. 140). No obstante la cita anterior, en las conclusiones afirma que la Corte Constitucional, en contraste con el Consejo de Estado, tiene una visión de la responsabilidad subjetiva, mientras que el Consejo de Estado se inclina por una responsabilidad objetiva, aunque reconociendo algunos matices a esta, como sucedió en la Sentencia del Consejo de Estado, Sección cuarta, del 12 de abril de 1985. M.P.: Enrique Low Murtra. Expediente 10850, citada por Galvis Arteaga (p. 133).

La naturaleza objetiva de la responsabilidad tiene implicaciones que afectan el debido proceso, ya que basta la existencia de un hecho para derivar de él la responsabilidad tributaria. La administración puede tomar una decisión que, orientada por dicha responsabilidad, desconozca los principios y garantías 
García, W., y Bedoya, O. El debido proceso en la liquidación de revisión...

del derecho penal que aplican, aunque con atenuaciones, en el derecho administrativo sancionador, bajo el concepto de que este tiene como fin la protección de la organización estatal y el funcionamiento de la misma. Si se analiza la liquidación de revisión que se refiere "al acto administrativo que concretiza la determinación oficial de un tributo" (Cermeño et al., 2017), en esta se imponen las sanciones por inexactitud y deberá estar suficientemente motivada con relación a los montos y sustentada con base en las pruebas, sujetas al principio de contradicción.

La indagación acerca del trámite de la liquidación de revisión muestra cómo la acción del ciudadano deberá encaminarse a probar que lo consignado en la liquidación obedece a la realidad de la actividad, como lo afirma Ramírez Torrado (2008) puesto que en el derecho administrativo sancionador, el principio de culpabilidad es su pilar.

El interrogante se refuerza por la lectura y análisis del texto de Galvis Arteaga (2019), quien explica que los principios y garantías procesales en derecho penal actúan de manera absoluta, mientras que en el derecho administrativo sancionador, se acepta que los principios y garantías del derecho penal se apliquen en forma relativa, garantizando las potestades del Estado, pero permitiendo al contribuyente el ejercicio de su defensa.

Otro de los autores que trata el tema de la responsabilidad es Restrepo Pineda (2015), quien introduce dudas importantes, pues evidencia que desde 1992 la propia Corte Constitucional, citando a los tratadistas García de Enterría y Ramón Fernández, ratifica la aplicación matizada de los principios y garantías penales al derecho administrativo sancionador, en especial en el derecho tributario, en lo que tiene que ver con la carga de la prueba y la presunción de inocencia. Sobre esta última afirma el autor que esta queda negada cuando se acepta la presunción de culpa en los casos de incumplimiento del deber constitucional de declarar, declarar extemporáneamente y hacerlo con inexactitudes, por cuanto "si se presume la culpa es porque la presunción de inocencia ha sido negada" (p. 83).

Es claro entonces que existe un conjunto normativo que obliga tanto a la Administración tributaria como al contribuyente, declarante, agente retenedor y responsable, además de una serie de principios, deberes y derechos, que la Constitución y la propia ley tributaria establecen para dar garantía al debido proceso en el caso de la liquidación de revisión. En lo que tiene que ver con la carga de la prueba, la Administración tributaria tiene el deber de aportar las pruebas mínimas que desvirtúen la presunción de inocencia.

\section{Conclusiones}

La indagación ha permitido entender que en el tema tributario opera la norma constitucional del debido proceso que le asigna al contribuyente, 
retenedor del IVA y al declarante una garantía específica para atender todo lo relacionado con el derecho de defensa. El desconocimiento de los distintos trámites y en especial la indebida notificación de la liquidación de revisión, así como la omisión del trámite de pruebas constituye una violación ostensible de los derechos constitucionales y legales.

Con relación a la hipótesis de la posible violación o desconocimiento de las normas que garantizan el debido proceso durante la etapa de fiscalización, prevalece la potestad de la administración de investigar con el fin de determinar la posible evasión o elusión, sobre el derecho del ciudadano a ser debidamente informado sobre el procedimiento. Se trata de una facultad inquisitiva que tiene el Estado a la cual no puede renunciar. La discusión administrativa del tributo conforme a las normas del Estatuto Tributario no recopila directamente la filosofía que contiene la presunción de inocencia que establece el artículo 83 de la Constitución Política, dado que el cimiento del requerimiento de información por parte de la DIAN parte de la presunción de la culpa en el actuar del contribuyente, responsable, agente retenedor o declarante, y es a este que le toca recaudar y presentar todo un acervo probatorio para demostrar todo lo contrario: su buena fe, siendo una discusión en sede administrativa no equitativa en las calidades de los sujetos, por un lado, se encuentra el Estado con todo su poder, estructura administrativa y función pública de un sinnúmero de empleados altamente capacitados y, por el otro, el contribuyente que cuenta con menos poder y que se encuentra limitado en su capacidad de recaudar material probatorio.

Es completamente necesario realizar una sensibilización al contribuyente, responsable, agente retenedor o declarante de mantener actualizada la información que reposa el Registro Único Tributario a fin no ser notificada en direcciones (física o electrónica) diferente y que no le permita realizar una defensa técnica de sus intereses. Al igual que, conocer los términos procesales para dar respuesta a los requerimientos, solicitar o aportar pruebas, dado que su desconocimiento o preclusión de términos no le permitirían obtener resultados óptimos en la discusión del tributo.

En consecuencia, no obstante, la participación pasiva del contribuyente en esta etapa, salvo si violan su intimidad o su seguridad, la controversia a que darían lugar las pruebas practicadas en ejercicio de la potestad de fiscalización, pueden ser controvertidas a partir de la notificación en debida forma de la liquidación de revisión, bien sea en sede administrativa o judicial, en el caso de haberse desconocido el derecho fundamental al debido proceso.

Es necesario considerar el interrogante planteado en relación con el desconocimiento de aspectos que son cruciales en lo que tiene que ver con el debido proceso, ya que se le desconoce al contribuyente la posibilidad del reconocimiento de las razones fácticas y jurídicas que desvirtúan los hechos 
García, W., y Bedoya, O. El debido proceso en la liquidación de revisión...

jurídicos sobre los cuales fundamenta la administración tributaria sus reparos, en relación con la no presentación de la declaración o con los errores de esta, que pueden provenir de una distinta interpretación contable y tributaria de un hecho, dentro de la controversia jurídica a que da lugar la liquidación de revisión.

Realmente el estudio y análisis refuerza un serio cuestionamiento de este tema y lo que significa la posición del contribuyente frente a la Administración Tributaria. Habría que pensar y debatir académicamente y en el ámbito de los especialistas en tributación acerca de los posibles mecanismos que permitan que el ciudadano tenga sus plenos derechos, para formular la posibilidad de un cambio en los principios orientadores de la liquidación de revisión de manera tal que la potestad de implementar mecanismos, para garantizar el flujo de los recursos del Estado, no esté en contra de los derechos fundamentales de los administrados, cuya actividad es la fuente de los ingresos, pero que dichos administrados son, además, los destinatarios de las funciones del Estado.

De los temas álgidos que debe contener el estudio académico es cimentar un cambio en el tipo de responsabilidad en materia tributaria, hoy prima la responsabilidad objetiva donde tan solo se verifica la comisión de un hecho, sin importar en lo más mínimo el elemento volitivo (voluntad y consciencia en el actuar). Al invertir el tipo de responsabilidad podríamos contar con una discusión en sede administrativa con mayores garantías que se derivan de la consagración constitucional del debido proceso como bien se ha hecho la normatividad penal que desde sus fundamentos normativos proscriben la responsabilidad objetiva y solo permiten la subjetiva, bien sea, a título de dolo o culpa.

\section{Referencias bibliográficas}

Acción de tutela, 11001-03-15-000-2014-02171-00 (Consejo de Estado Sala de lo Contencioso Administrativo Sección Cuarta 7 de Abril de 2016).

Calle Calderón , A. L. (2000). Bases para una fundamentación político-constitucional del debido proceso. Nuevo Foro Penal $N^{\circ} 63$ Universidad Eafit, 45-69.

Cardona J., J. (2012). Modelo hermenéutico del debido proceso en Colombia. Estudios de Derecho -Estud. Derecho- Vol. LXIX. No 153, junio 2012. Facultad de Derecho Universidad de Antioquia, Medellín, 215-243.

Carvajal, B. (2010). Alcances y limitaciones del debido proceso en el procedimiento administrativo. Revista Digital de Derecho Administrativo $N^{\circ} 4,7-21$.

Cea E., J. (2007). Proyecciones de la separación de poderes en el Estado Contemporáneo. Anuario de Derecho Constitucional Latinoamericano., 147-161.

Cermeño, C., De Bedout G., J., Andrés G., S., y Clopatofsky D., C. (2017). Procedimiento Tributario. Teoría y Práctica. Bogotá: Legis Editores.

Chinchilla, T. (2016). El Estado de Derecho como modelo político jurídico. Revistas UPB, 37-66. 
Consejo de Estado, Sentencia del 22 de febrero de 2018. Radicación: 73001-23-33-0002012-00174-01 (20478) (Consejo de Estado [Magistrado ponente: Julio Piza] 2018).

Consejo de Estado Sala de Consulta y Servicio Civil [Magistrado ponente: Álvaro Namén Vargas]. (2017). Radicación número: 11001-03-06-000-2016-00210-00(2316). Consulta sobre obre el alcance de los artículos 68 y 69 de la Ley 1437 de 2011 que regulan la notificación por aviso y la notificación electrónica. Bogotá: Consejo de Estado.

Consejo de Estado- Sala de lo Contencioso Administrativo, Recurso de apelación Radicación: 25000233700020140129101 (23288) (Consejo de Estado - Sala de lo Contencioso Administrativo Sección Cuarta [Magistrada ponente: Stella Jeannette Carvajal Basto 2018).

Consejo de Estado- Sección Primera, Sentencia 13001233100020010202301, 03/11/2016 (Consejo de Estado [Magistrado ponente: Roberto Augusto Serrato] 2016).

Consejo de Estado. Sala de lo Contencioso Administrativo [Magistrada ponente: Stella Jeannette Carvajal Basto]. (8 de septiembre de 2017). Sentencia radicación 05001-2333-000-2014-01479-01 (22342). Bogotá: Consejo de Estado.

Consejo de Estado-Sala de Consulta y Servicio Civil, Radicación 11001-03-06-000-201600210-00(2346 (Consejo de Estado [Magistrado ponente: Álvaro Namén Vargas] 2017).

Corte Constitucional , Sentencia T-445 de 1992 (Corte Constitucional [Magitrado ponente: Simón Rodríguez] 6 de julio de 1992).

Corte Constitucional , Sentencia C-214 de 1994 (Corte Constitucional [Magistrado ponente: Antonio Barrera Carbonell] 28 de abril de 1994).

Corte Constitucional, Sentencia T-589 de 1999 (Corte Constitucional [Magistrado ponente: Eduardo Cifuentes Muñoz] 13 de agosto de 1999).

Corte Constitucional , Sentencia C-096 de 2001 (Corte Constitucional [Magistrado ponente: Álvaro Tafur Galvis] 31 de enero de 2001).

Corte Constitucional, Sentencia T-171 de 2006 (Corte Constitucional [Magistrada ponente: Clara Inés Vargas Hernández] 7 de marzo de 2006).

Corte Constitucional , Sentencia T-404 de 2014 (Corte Constitucional [Magistrado ponente: Jorge Iván Palacio Palaciol 26 de junio de 2014).

Corte Constitucional, Sentencia C-034 de 2014 (Corte Constitucional [Magistrada ponente:

María Victoria Calle Correal 29 de enero de 2014).

Corte Constitucional , Sentencia C-060 de 2018 (Corte Constitucional [Magistrada ponente:

Gloria Stella Ortiz Delgadol 7 de junio de 2018).

Corte Constitucional [Magistrado ponente: Jaime Córdoba Triviño]. (2001). Sentencia C-710 de 2001. Bogotá: Corte Constitucional.

Corte Constitucional, Sentencia C-600 de 2015 (Corte Constitucional [Magistrada ponente:

María Victoria Calle Correa] 16 de septiembre de 2015).

Corte Constitucional, Sentencia C-481 de 2019 (Corte Constitucional [Magistrado ponente:

Alejandro Linares Cantillo] 16 de Octubre de 2019).

Fernández Arbeláez, I. M. (2015). Derecho Procesal Administrativo y Contencioso Administrativo.

Armenia: Editorial Universitaria-Universidad la Gran Colombia Armenia.

Ferrajoli, L. (1995). Derecho y razón. Madrid: Trotta. 
García, W., y Bedoya, O. El debido proceso en la liquidación de revisión...

Galvis A., J. (2019). El debido proceso en materia tributaria frente al régimen de responsabilidad objetiva. Revista de Derecho Fiscal $N^{\circ} 14$, Universidad Externado de Colombia, Bogotá, 121-142.

Galvis Arteaga, J. (2019). El debido proceso en materia tributaria frente al régimen de responsabilida objetiva. Revista de Derecho Fiscal $N^{\circ} 14,121-142$.

López P., A., \& Gutiérrez D., M. (2001). El sistema tributario durante la Edad Media. Boletín Jurídico de la Universidad Europea de Madrid, 10.

Martinez Jurado, D. (2018). El Soft Law en Derecho Administrativo y su control judicial en Colombia. Revista Digital de Derecho Administrativo $N^{\circ} 20$, 289-343.

Montesquieu. (1906). El Espíritu de las Leyes. Madrid: Biblioteca de Derecho y de Ciencias Sociales.

Pérez Ortiz, R. E. (2013). Eficacia y validez del acto administrativo. Bogotá: Universidad Nacional Maestría en Derecho Admintrativo .

Perilla-Zamudio, J. F. (2015). El acto administrativo como expresión de la función administrativa. In Vestigium Ire Vol. $9 N^{\circ} 1,175-183$.

Piza R., J. (2008). El régimen fiscal en la Constitución de 1991. Revista Derecho del Estado $N^{\circ}$ 21 Universidad Externado de Colombia, Bogotá, 51-80.

Piza R., J. (2014). La función de fiscalización tributaria en Colombia. Revista de Derecho Fiscal 7. Universidad Externado de Colombia, Bogotá, 231-277.

Ramírez Torrado, M. L. (2008). Consideraciones de la Corte Constitucional acerca del principio de culpabilidad en el derecho administrativo sancionador. Revista de Derecho No. 29, 153-177.

Restrepo Herrera, C. (2009). El acceso a la justicia dentro de un debido proceso. Universitas Estudiantes, 63-73.

Restrepo Pineda, C. M. (2015). Los principios y garantías del debido proceso penal y su aplicación en materia tributaria. Ratio Iuris Vol. 10, número 20, 61-86.

Romero-Molina, C., Grass-Suárez, Y., \& García-Caicedo, X. (2013). Principios constitucionales que rigen el sistema tributario. Derecho y políticas públicas, vol 15, número 17, 67-77.

Santofimio Gamboa, J. (2003). Tratado de Derecho Administrativo. Acto Administrativo Procedimiento, Eficacia y Validez. Bogotá: UniVersidad Externado de Colombia.

Sentencia , 15001233300020130003501 N$^{\circ}$ interno 20890 (Consejo de Estado Sala de lo Contencioso Administrativo Sección Cuarta 20 de Septiembre de 2017).

Sentencia C-012 de 2013, Exped. D-9195 (Corte Constitucional 23 de Enero de 2013).

Sentencia C-034 de 2014, Exped. D-9566 (Corte Constitucional 29 de Enero de 2014).

Vega, A. (2014). Efectos de la indebida notificación de los actos administrativos tributarios emitidos por la Dian en la etapa de liquidación o determinación de los tributos de orden nacional . Revistas U.Externado, 207-2013. 